\title{
Article \\ A Retrospective Cohort Study of Clinical Factors Associated with Transitions of Care among COVID-19 Patients
}

\author{
Dennis Swearingen ${ }^{1,2}$, Gregory Boverman ${ }^{3, *} *$, Kristen Tgavalekos ${ }^{3}$, David P. Noren ${ }^{3}$, Shreyas Ravindranath ${ }^{3}$, \\ Erina Ghosh ${ }^{3}$, Minnan Xu ${ }^{3}$, Lisa Wondrely ${ }^{3}$, Pam Thompson ${ }^{1}$, J. David Cowden ${ }^{1}$ and Corneliu Antonescu ${ }^{1,2(1)}$ \\ 1 Department of Medical Informatics, Banner Health, Phoenix, AZ 85012, USA; \\ dennis.swearingen@bannerhealth.com (D.S.); Pam.Thompson@bannerhealth.com (P.T.); \\ jdavid.cowden@bannerhealth.com (J.D.C.); corneliu.antonescu@bannerhealth.com (C.A.) \\ 2 Department of Biomedical Informatics, University of Arizona College of Medicine, Phoenix, AZ 85004, USA \\ 3 Connected Care and Personal Health Department, Philips Research North America, Cambridge, MA 02141, \\ USA; kristen.tgavalekos@philips.com (K.T.); david.noren@philips.com (D.P.N.); \\ shreyas.ravindranath@philips.com (S.R.); erina.ghosh@philips.com (E.G.); Minnan.Xu@philips.com (M.X.); \\ lisa.wondrely@philips.com (L.W.) \\ * Correspondence: gregory.boverman@philips.com
}

\section{check for} updates

Citation: Swearingen, D.; Boverman G.; Tgavalekos, K.; Noren, D.P.; Ravindranath, S.; Ghosh, E.; Xu, M.; Wondrely, L.; Thompson, P.; Cowden, J.D.; et al. A Retrospective Cohort Study of Clinical Factors Associated with Transitions of Care among COVID-19 Patients. J. Clin. Med. 2021 10, 4605. https://doi.org/10.3390/ jcm10194605

Academic Editor: Marcello Covino

Received: 15 September 2021

Accepted: 29 September 2021

Published: 8 October 2021

Publisher's Note: MDPI stays neutral with regard to jurisdictional claims in published maps and institutional affiliations.

Copyright: (c) 2021 by the authors. Licensee MDPI, Basel, Switzerland. This article is an open access article distributed under the terms and conditions of the Creative Commons Attribution (CC BY) license (https:// creativecommons.org/licenses/by/ $4.0 /)$.
Abstract: Coronavirus Disease 2019 (COVID-19) is an international health crisis. In this article, we report on patient characteristics associated with care transitions of: (1) hospital admission from the emergency department (ED) and (2) escalation to the intensive care unit (ICU). Analysis of data from the electronic medical record (EMR) was performed for patients with COVID-19 seen in the ED of a large Western U.S. Health System from April to August of 2020, totaling 10,079 encounters. Of these, 5172 resulted in admission as an inpatient within $72 \mathrm{~h}$. Inpatient encounters $(n=6079)$ were also considered for patients with positive COVID-19 test results, of which 970 resulted in a transfer to the ICU or in-hospital mortality. Laboratory results, vital signs, symptoms, and comorbidities were investigated for each of these care transitions. Different top risk factors were found, but two factors common to hospital admission and ICU transfer were respiratory rate and the need for oxygen support. Comorbidities common to both settings were cerebrovascular disease and congestive heart failure. Regarding laboratory results, the neutrophil-to-lymphocyte ratio was associated with transitions to higher levels of care, along with the ratio of aspartate aminotransferase (AST) to alanine aminotransferase (ALT).

Keywords: COVID-19; triage; care transitions

\section{Introduction}

The Coronavirus Disease 2019 (COVID-19) pandemic began in December 2019, with the first case reported in the United States in January 2020. As of 22 June 2021, there were 178 million confirmed cases and 3.8 million deaths reported globally [1]. The pandemic has severely strained hospital operations and care delivery. In response, hospitals have put in place a range of strategies to address such challenges across care settings. For example, emergency departments (EDs) have adapted or created new practices to address the surge of patients who potentially present with COVID-19. In a primer for emergency physicians, it was advised that patients with mild symptoms, no significant comorbidities, and the ability to self-quarantine should be discharged home [2]. Furthermore, predictors of outcomes can be used to support the clinical management of patients and to inform resource allocation decisions. At George Washington University, a clinical decision pathway for emergency department (ED) triaging was introduced to protect ED bed capacity [3]. Among the pathway components was a labeling of patients as high risk or low risk according to age, heart rate, and temperature criteria.

In one study of patients hospitalized for COVID-19, approximately 30\% required ICU care [4]. A key element of preparation for patient surges is a plan for increasing critical 
care capacity as needed, for example by expanding to other units like post-anesthesia and step-down units [5]. Given the challenges associated with capacity, resource management, staffing, and triage [6], predictors of the need for a patient to be transitioned to the ICU could be quite valuable.

The characteristics, comorbidities, and outcomes of COVID-19 patients have been studied in various regions around the world - Wuhan, China [7], the Lombardy region of Italy [8], and the New York City area in the United States [9], to name a few. The objective of this study is to identify factors associated with care transitions for a large cohort of COVID-19 patients within an integrated regional health system. The hypothesis is that several clinical measurements and conditions would be identifiable as associated with the transfer of these patients from the ED to the inpatient floor and also to the ICU.

\section{Materials and Methods}

Electronic medical record (EMR) data was retrospectively obtained and de-identified to a limited dataset, for patients seen in a large U.S. health system. This regional system is broad-based, consisting of approximately 30 acute-care hospitals which range from community to tertiary-care facilities located in the states of Arizona, California, Colorado, Nebraska, Nevada, and Wyoming. All cases across locations were aggregated and variations in practice or procedure between different facilities were not explored. Patients presenting to the facilities between 1 April and 30 July 2020 were considered for inclusion and a diagnosis of COVID-19 was identified based on the assignment of ICD10 code U07.1.

To validate that the patient transitions extracted from the EMR made sense, a network graph was created to illustrate transitions through the health system. Nodes were used to represent location types or discharge dispositions. Miscellaneous location types with low counts (e.g., obstetrics ward, behavioral health ward, etc.) were grouped together. Also, miscellaneous discharge dispositions with low counts (e.g., discharge to hospice, discharge to jail, left against medical advice, etc.) were grouped together. For this reason, and also because a single patient may have experienced a transition multiple times, the sum of the edges originating from a node was not intended to add up exactly to the number in the node. Rather, the numbers indicated the general proportion of encounters in each location.

The patients were divided into two groups: those who presented to the ED and those who were admitted to the hospital from a non-ED setting. The first group was further divided into four cohorts based on disposition at ED discharge. Cohort A consisted of patients who were discharged to home and were not admitted as an inpatient within $72 \mathrm{~h}$. Cohort B consisted of patients who were discharged to home but were admitted as an inpatient within $72 \mathrm{~h}$. Cohort $C$ were patients who were admitted to the hospital at the end of their ED visit. The remaining patients, consisting of patients who were transferred to another facility or left against medical advice, were excluded from the analysis. Among the patients who were directly admitted to the hospital, patients who were directly admitted to the ICU were excluded from the analysis. Inpatient deterioration was defined as requiring transfer to the ICU or experiencing in-hospital mortality. Among all patients admitted to a non-ICU unit, the patients with a missing discharge disposition were excluded. The remaining inpatients were subdivided into two cohorts: Cohort D consisted of inpatients who did not deteriorate and Cohort E consisted of inpatients who did deteriorate. Table 1 provides a summary of cohort descriptions and their endpoints.

Demographic factors (age, race, ethnicity, sex) are reported for all cohorts. For summarizing demographics, we used the tableone package for Python 3.0 (Wilmington, DE, USA) $[10,11]$. Continuous variables were summarized as a mean with standard deviation (SD) in parentheses. Categorical variables were summarized as counts with the percentage of their respective classes in parentheses. For categorical variables with at least 5 counts per category and class, a Chi-squared test was performed to test the null hypothesis that there is no difference in the frequencies for each category between the two classes. For continuous variables, a two-sample $t$-test was performed to test the null hypothesis that the means of the two populations were equal. $p$-values describe the probability of observing 
results at least as extreme under the assumption that the null hypothesis is correct. A $p$-value less than 0.05 was used as the significance level below which the null hypothesis was rejected.

Table 1. Description of cohorts.

\begin{tabular}{cll}
\hline Cohort ID & \multicolumn{1}{c}{ Description } & \multicolumn{1}{c}{ Endpoint } \\
\hline $\mathrm{A}$ & $\begin{array}{l}\text { ED patients discharged to home and not admitted as } \\
\text { inpatient within } 72 \mathrm{~h}\end{array}$ & $72 \mathrm{~h}$ after ED discharge \\
\hline $\mathrm{B}$ & $\begin{array}{l}\text { ED patients discharged to home and } \\
\text { admitted as inpatient within } 72 \mathrm{~h}\end{array}$ & $72 \mathrm{~h}$ after ED discharge \\
\hline $\mathrm{C}$ & ED patients admitted to hospital in same encounter & Hospital admit \\
\hline $\mathrm{D}$ & Inpatients who do not go to ICU or die in-hospital & Hospital discharge \\
\hline $\mathrm{E}$ & $\begin{array}{l}\text { Inpatients who deteriorated (admitted to ICU or } \\
\text { died in-hospital) }\end{array}$ & Deterioration \\
\hline
\end{tabular}

ED: emergency department; ICU: intensive care unit.

Charlson comorbidities were specified as defined in Quan et al. 2011 [12] and were calculated from patient diagnosis codes (ICD10) using the ICD package in the R statistical software [13]. Note that patient diagnosis codes were charted based on treatment during the visit and may not have reflected the patient's full history of chronic disease. Three sets of cohort comparisons were performed, and they are described in Table 2 along with the time range over which data was considered.

Table 2. Description of comparisons performed.

\begin{tabular}{|c|c|c|c|}
\hline $\begin{array}{l}\text { Comparison. } \\
\text { ID and Label }\end{array}$ & $\begin{array}{l}\text { Cohorts } \\
\text { Compared }\end{array}$ & Long Description & $\begin{array}{l}\text { Values Used for } \\
\text { Non-Categorical Data }\end{array}$ \\
\hline \multirow{2}{*}{$\begin{array}{c}1 \\
\text { “ED admission" }\end{array}$} & A & $\begin{array}{l}\text { ED patients discharged to } \\
\text { home and not admitted } \\
\text { as inpatient within } 72 \mathrm{~h}\end{array}$ & \multirow{2}{*}{ Last value during ED stay } \\
\hline & B \& C & $\begin{array}{l}\text { ED patients who were } \\
\text { admitted to the hospital } \\
\text { within } 72 \mathrm{~h}\end{array}$ & \\
\hline \multirow{2}{*}{$\begin{array}{c}2 \\
\text { "ED bounce-back" }\end{array}$} & A & $\begin{array}{l}\text { ED patients discharged to } \\
\text { home and not admitted } \\
\text { as inpatient within } 72 \mathrm{~h}\end{array}$ & \multirow{2}{*}{ Last value during ED stay } \\
\hline & B & $\begin{array}{l}\text { ED patients discharged to } \\
\text { home and admitted as } \\
\text { inpatient within } 72 \mathrm{~h}\end{array}$ & \\
\hline \multirow{2}{*}{$\begin{array}{c}3 \\
\text { "Inpatient } \\
\text { deterioration" }\end{array}$} & $\mathrm{D}$ & $\begin{array}{l}\text { Inpatients who do not go } \\
\text { to ICU or die in-hospital }\end{array}$ & $\begin{array}{l}\text { Most recent value measured } \\
\text { at midpoint of hospital stay }\end{array}$ \\
\hline & $\mathrm{E}$ & $\begin{array}{l}\text { Inpatients who } \\
\text { deteriorate (admitted to } \\
\text { ICU or die in-hospital) }\end{array}$ & $\begin{array}{l}\text { Most recent value measured } \\
X \text { hours prior to deterioration } \\
\qquad(X=4,12)\end{array}$ \\
\hline
\end{tabular}

Comparisons 1, 2, and 3 each include an outcome linked with higher acuity (ED admission, ED bounce-back, or inpatient deterioration, respectively) that is compared to an outcome of lower acuity. To study the higher acuity outcomes, univariate logistic regression models were built for different variables-comorbidities, symptoms, vital signs, and lab results. All non-categorical variables were standardized to have zero mean and unit variance before model generation. For those covariates deemed to be highly statistically significant ( $p$-value less than 0.001 ), we ordered them by the absolute value of the logistic regression coefficient, showing the top 30 covariates for each outcome (or fewer, if there were not 30 that were significant). 
Multivariate results were generated using stepwise regression with a forward-backward procedure where covariates were included if their $p$-values in the multivariate fit were less than a given threshold (0.01). Likewise, covariates were excluded if their $p$-values in the multivariate fit exceeded a given threshold (0.05).

This project was a part of an ongoing retrospective deterioration detection study approved by the Institutional Review Board of the health system. The study was not registered with ClinicalTrials.gov because it is non-interventional (observational) clinical research and does not meet the definition of an applicable clinical trial.

\section{Results}

Figure 1 is a network graph that illustrates patient transitions through the health system. Patient discharge from the ED to home was the most prevalent transition type $(51 \%)$. Of the ED patients who were admitted to the hospital, approximately $32 \%$ were placed in a low acuity general ward first, while approximately $17 \%$ were admitted to a higher acuity setting (ICU or Step). Note that in-hospital death occurred mostly in the ICU setting.

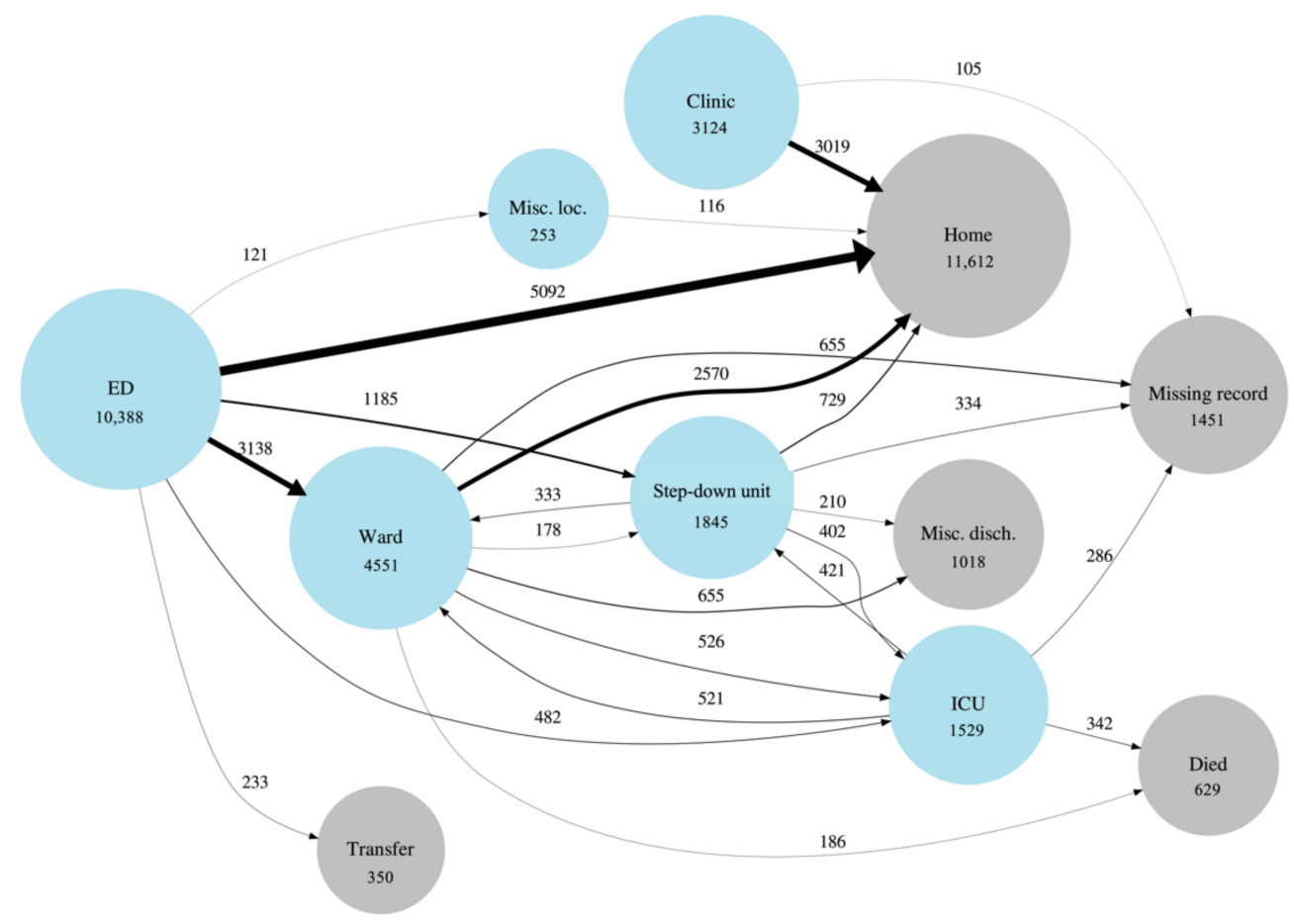

Figure 1. Graphical depiction of COVID patient flow through the healthcare system. Blue circles (nodes) represent location types within the system. Grey circles represent discharge dispositions. Circle diameters are proportional to the (natural log of the) number of patients who passed through a location type at least once during an encounter. Line (edge) widths are linearly proportional to the number of times a transition occurred and the edges are also labeled with this number. The "Misc. loc." node stands for miscellaneous locations that have been grouped together due to low counts and for privacy purposes. The "Misc. disch." node stands for miscellaneous discharge dispositions that have been grouped together. For visualization and privacy purposes, transitions are only shown when they have more than 100 counts.

We identified 11,406 unique patients/subjects with the COVID-19 diagnosis who had 15,271 unique encounters with the hospital system within the time range considered. Figure 2 shows the CONSORT diagram for patients included in the study. See Tables A1 and A2 for cohort demographics. 


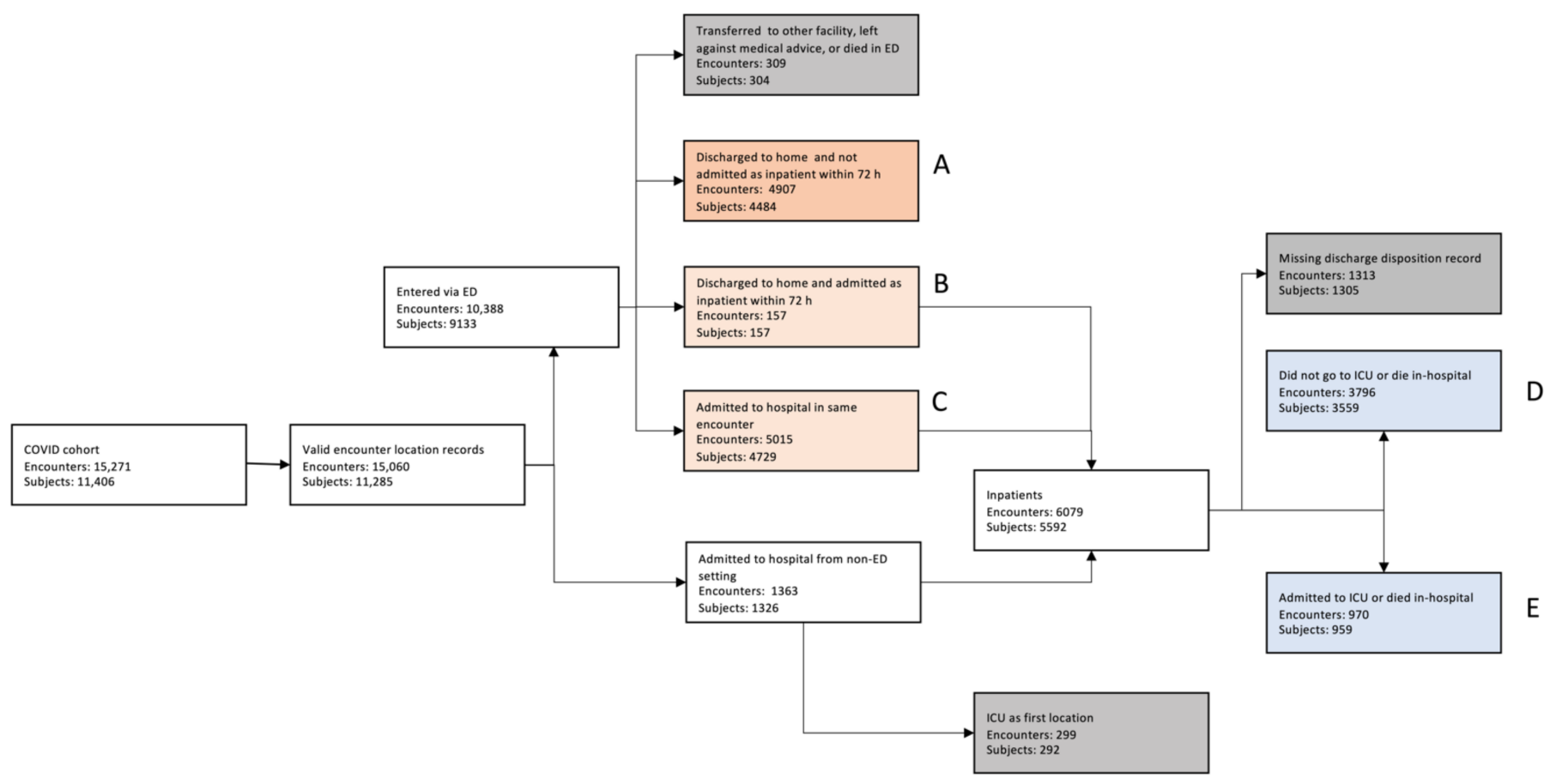

Figure 2. CONSORT diagram for patients included in the study.

\subsection{Emergency Department (ED) Cohort}

The following Sections 3.1.1 and 3.1.2, report results for Comparisons 1 (ED admission) and 2 (ED bounce-back), as described in Table 2. These investigate the factors associated with transitions of care from the ED.

\subsubsection{Comorbidities and ED Transitions}

Logistic regression log-odds ratios correlating comorbidities to the outcomes of interest for Comparison 1 (ED admission) are shown in . Only statistically significant correlations $(p<0.01)$ are displayed and they are adjusted for age. Results for Comparison 2 (ED bounce-back) are shown in the Appendix A in Figure A2.

\subsubsection{Correlates of Vital Signs, Symptoms, and Laboratory Results to ED Transitions}

Logistic regression log odds coefficients for the outcomes of interest are shown in Figure 3, where Comparison 1 (ED admission) is shown in (a), and Comparison 2 (ED bounce-back) is shown in (b). As previously, only statistically significant correlations $(p<0.01)$ are shown. We show univariate and multivariate coefficients in the same figure with no values shown for parameters that did not appear in the multivariate model. Here the variables are sorted by the maximum of the absolute values of the univariate and multivariate coefficients (this applies to all figures of this type that follow). Quantitative multivariate results for comparisons 1 and 2 are shown in Tables A3 and A4.

\subsection{Non-Critical Inpatient Cohort}

The following Sections 3.2.1 and 3.2.2, report results for Comparison 3 (inpatient deterioration).

\subsubsection{Correlations of Comorbidities with Inpatient Deterioration}

The correlations of comorbidities to the outcome for Comparison 3 (inpatient deterioration) are shown in, adjusted for age. Of note, relatively few comorbidities were correlated to the outcome with statistical significance and the coefficients for those that were significant were smaller than for Comparison 1 (ED admission). 

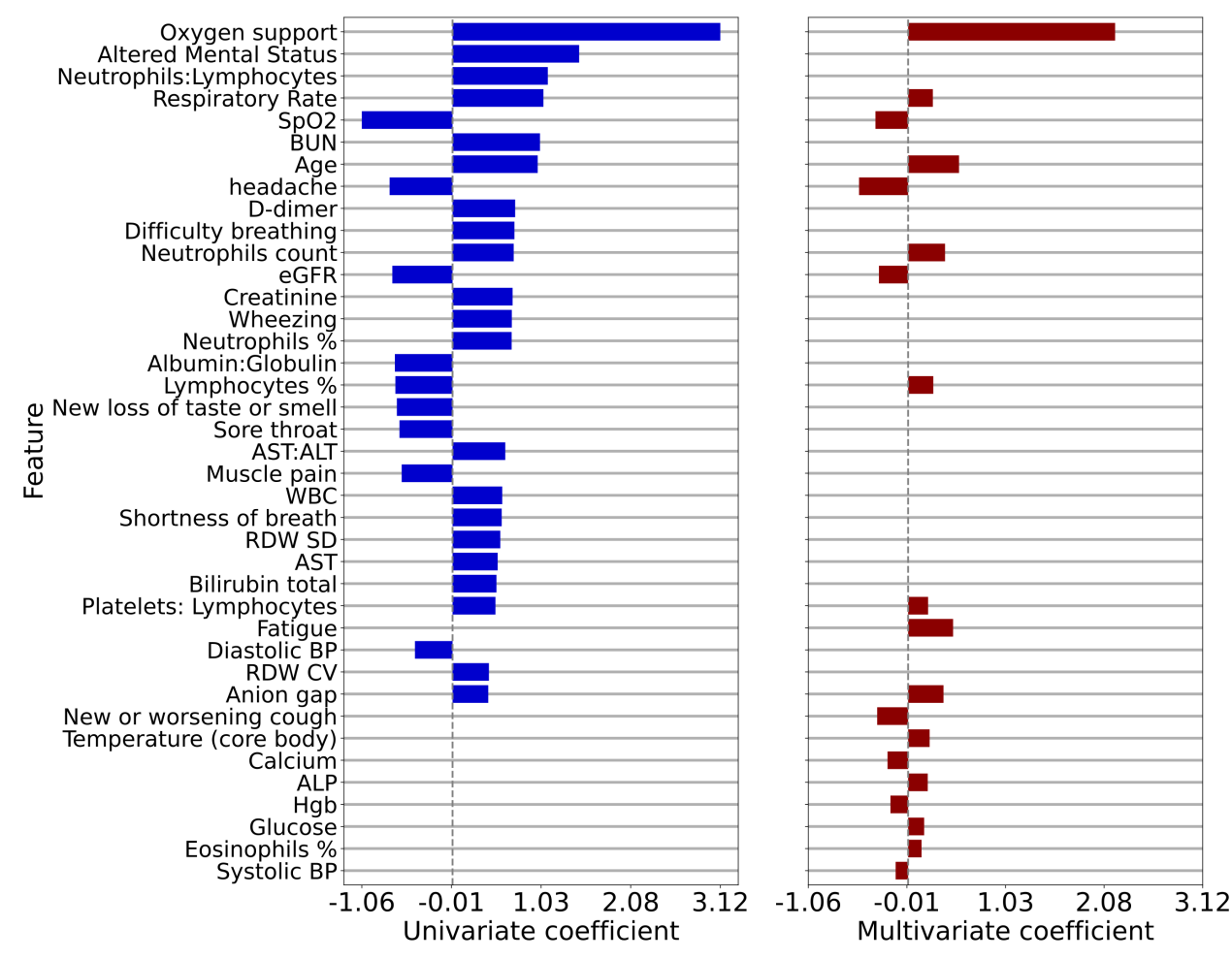

(a)
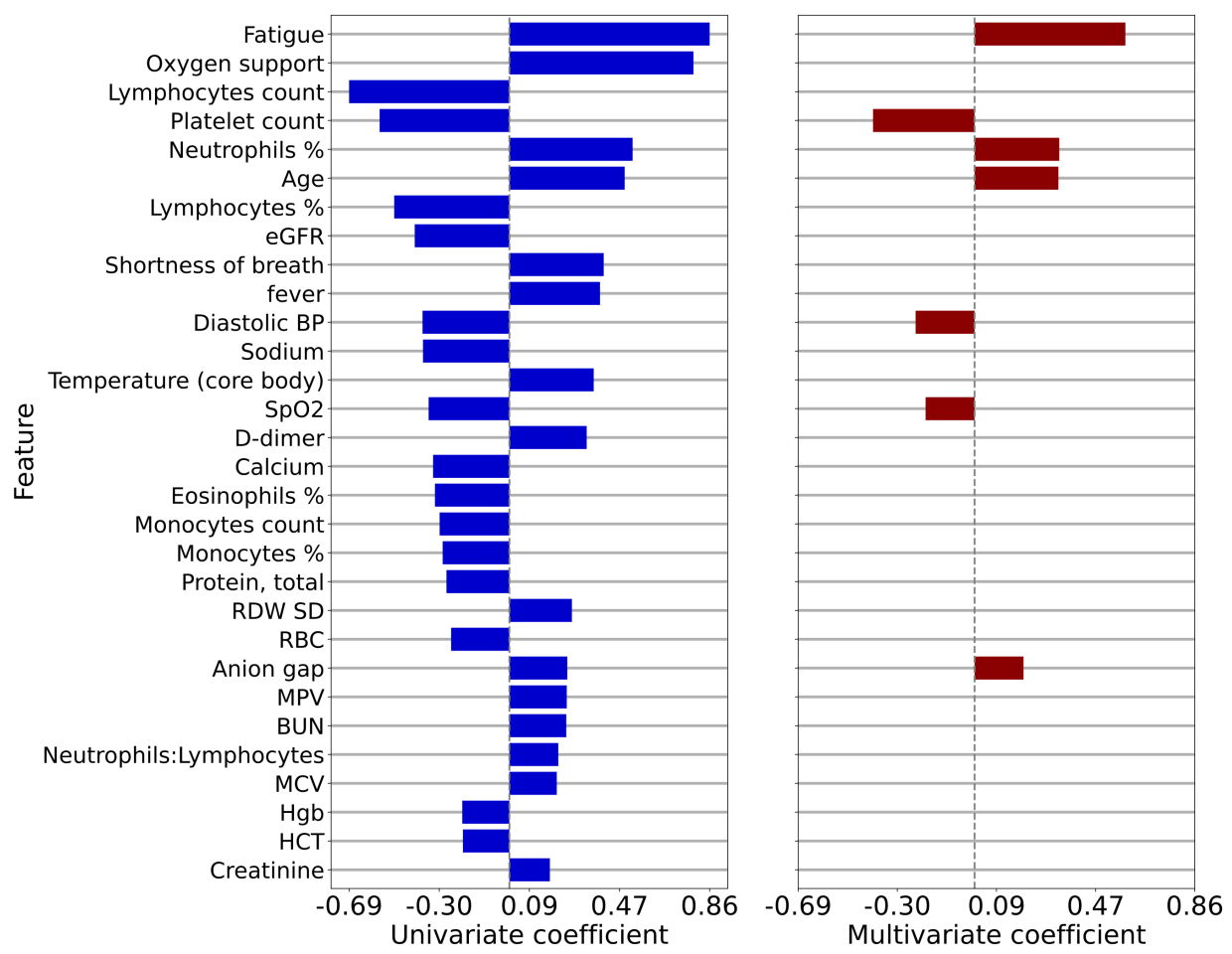

(b)

Figure 3. Univariate and multivariate logistic regression coefficients for comparisons 1 (a) ED admission and 2 (b) ED bounce-back.

3.2.2. Correlations of Symptoms, Vital Signs, and Laboratory Results with Inpatient Deterioration

The univariate and multivariate logistic regression log-odds ratios correlating measured parameters to the outcome of patient deterioration in $12 \mathrm{~h}$ are shown in Figure $4 \mathrm{a}$ 
and to the outcome of patient deterioration in $4 \mathrm{~h}$ are shown in Figure $4 \mathrm{~b}$, where only statistically significant correlations $(p<0.01)$ are displayed.
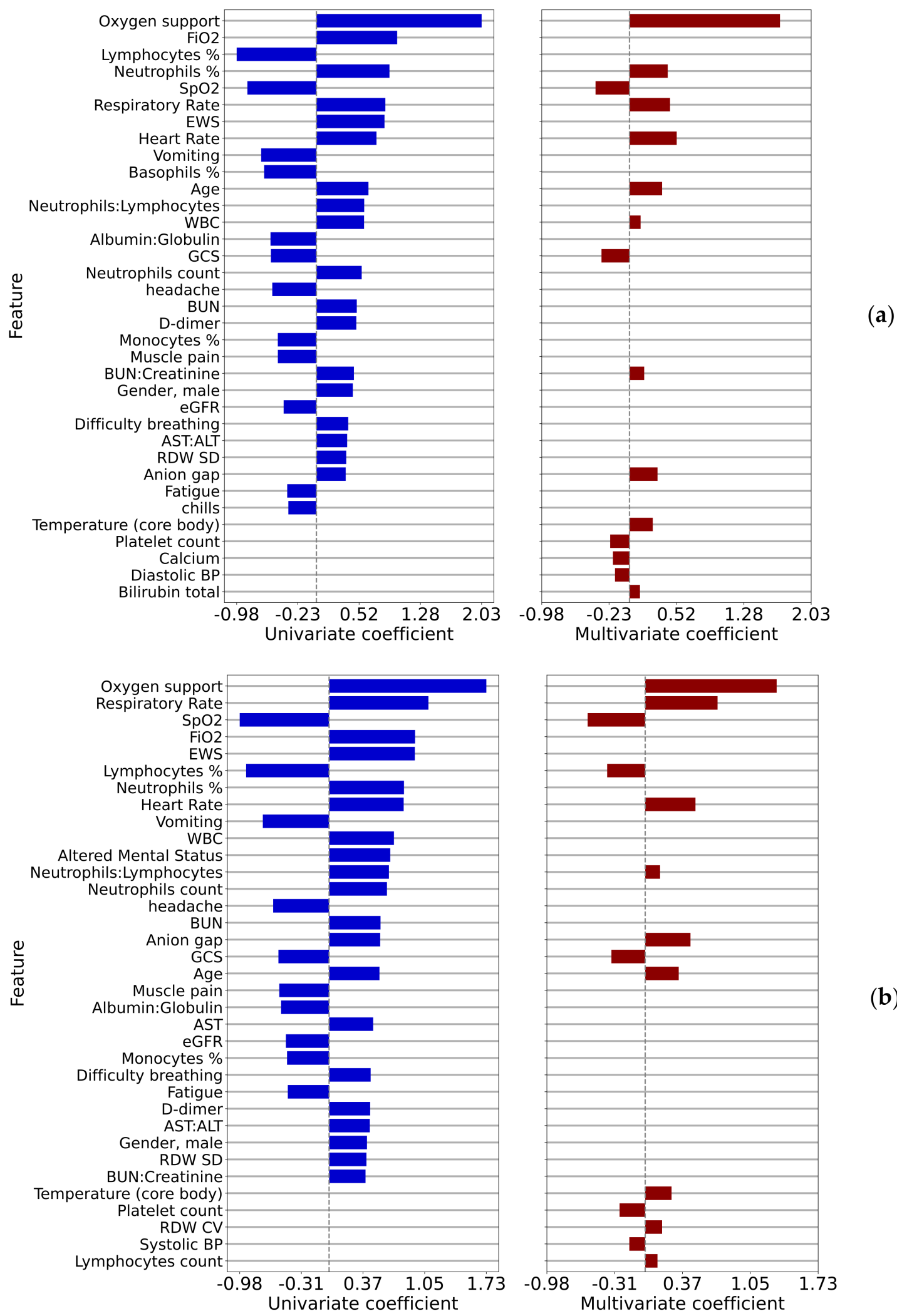

(b)

Figure 4. Univariate and multivariate regression coefficients for comparison 3 (a) $12 \mathrm{~h}$ prior to the event and (b) $4 \mathrm{~h}$ prior to the event. 
Vital signs, notably heart rate and respiratory rate, are among the strongest correlates. In the $12-\mathrm{h}$ case, the percentage of neutrophils is a sign of imminent deterioration. The common variables to all four multivariate models were $\mathrm{SpO} 2$, anion gap, age, neutrophilrelated variables (count, \%, or ratio to lymphocytes), platelet-related variables (count or ratio to lymphocytes), and blood pressure (systolic or diastolic). Quantitative results for these two-time points are shown in Table A5 for the 12-h case and in Table A6 for the 4-h case

\section{Discussion}

The COVID-19 pandemic forced hospital systems and care providers to evaluate and treat patients while under significant resource constraints. Part of the challenge in doing so was determining the appropriate care transitions for these patients, including whether to admit patients from the ED to the floor or to transfer from the floor to the ICU. Each of these transition decisions requires an assessment of patient acuity, which was challenging given the sparsity of information about COVID-19, particularly early in the pandemic.

The selected date range for this study is 1 April through 30 July 2020. It was chosen to reduce bias or inconsistency from factors such as changes in clinical standards, overall bed management, and therapeutic interventions. These changes were seen, sometimes to a significant extent, as the pandemic moved through waves and also as understanding increased. By focusing on the first wave of a particular health system's geography, greater clarity may be present from the data.

We have developed four multivariate models correlating measured patient covariates with the outcomes described in Table 2. The summary results for these models can be found in Table A7, where we have computed the rank of each covariate in each of the models and counted the number of models in which that covariate appears. The analysis of these summary results tells us which covariates are correlated to outcomes across all care settings vs. those covariates which are specific to settings. We found that $\mathrm{SpO} 2$, age, and anion gap appeared with high statistical significance and relatively high ranks in all of the models. Of these, perhaps only anion gap is surprising, possibly indicating the risk of ketoacidosis in diabetic patients. Oxygen support, platelet count, core body temperature, and respiratory rate appeared in three of the four models. We further note that percentages of lymphocytes or neutrophils (which are in some sense complementary as these are the most common white blood cells) appear in all four of the models. Similarly, systolic or diastolic blood pressure, which are also complementary, appear in all four of the models as well. Finally, some covariates appear more important in some care settings vs. others. For example, self-reported fatigue appears to be very important to the decision to admit as an inpatient (given its high ranking as shown in Figure 3b) but less important for ICU transfer. Likewise, heart rate is very important to the decision to admit a patient to the ICU but less important in the initial admission decision from the ED.

Univariate analysis of comorbidities and complications related to admission as inpatient from the ED is presented in Figure A1. It may be interesting to note that cardiovascular comorbidities such as cerebrovascular disease, congestive heart failure, and peripheral vascular disease have higher log-odds ratios as compared to pulmonary comorbidities. With the early focus of COVID-19 as a pulmonary-oriented infection and the need for respiratory support, some readers may find this unexpected. However, this finding is similar to a recently-published multivariate analysis which showed that asthma, chronic obstructive pulmonary disease, and use of corticosteroid treatment were not independent risk factors for the increased acuity outcomes of ICU admission or death [14]. On the other hand, cardiovascular comorbidities are known to be frequently present among COVID-19 patients and may be associated with adverse clinical events and mortality [15,16]. Among clinical characteristics, oxygen support had by far the highest correlation with admission as an inpatient, with the greatest inverse correlation being $\mathrm{SpO} 2$. These two findings are perhaps expected and are indicative of the effects of COVID-19 on the respiratory system, even in patients without known pulmonary comorbidities or complications. 
A notable item with univariate log-odds ratios associated with inpatient admission is d-dimer, which is among the top biomarkers associated with COVID-19 severity [17-19]. A less-expected association that arose was red blood cell distribution width (RDW). However, RDW is recognized as a biomarker for all-cause mortality and several studies have now identified increased RDW as a biomarker for COVID-19 severity as well [20-22]. Another interesting association with acuity was aspartate aminotransferase (AST)-dominant aminotransferase elevation, which has been reported in the literature [23]. Furthermore, the presence of certain symptoms such as headache, sore throat, and muscle pain are inversely associated with admission; perhaps this could be explained by the concept that patients with non-COVID infectious, or non-infectious, conditions that typically do not require admission may frequently present with these symptoms.

One potentially interesting and novel finding is the relatively strong association of moderate or severe liver disease to admission from the ED (Figure A1) and inpatient deterioration (Figure A3). These comorbidities are not generally believed to be associated with COVID-19 and a potentially confounding factor is obesity. Perhaps there are mechanisms related to contributing conditions such as fatty liver disease, alcoholic disease, NASH (non-alcoholic steatohepatitis), or viral hepatitis, which might be independent risk factors in and of themselves.

Of interest for further investigation are the associations of higher \% neutrophils and lower \% lymphocytes with higher acuity, which were found also in other publications [24,25]. Potential causes for this finding of relative lymphopenia are the inflammatory cytokine storm, exhaustion of T cells, infection of T cells, and interference with T cell expansion [26]. Zhu et al. note that in addition to a high neutrophil to lymphocyte ratio, a low ratio may also be associated with mortality, indicating a nonlinear association with acuity [27].

Addressing the concept of ED bounce-backs, studied in Comparison 2, can be quite useful for a health system. Many resources and clinical outcomes may be impacted by patients who were sent home but then presented within $72 \mathrm{~h}$ and resulted in hospital admission. Attention to the symptoms, vitals, and lab results that correlate in a positive or negative risk for this phenomenon could not only save time and expense for both the health system and patients, but also lead to potential improvement in clinical outcomes. Figure $3 b$ that the top three risks include the symptom of fatigue, the need for nasal canula oxygen support, and the increase in the percent neutrophils value. On the other side of the log-odds ratios were found decreased percentage and number of lymphocytes, platelet count, and eGFR.

A patient who suffers deterioration rather acutely, within 4-12 h, is an important situation to identify within a hospital. Various risk models and algorithms have been developed in this space for clinical conditions such as sepsis. Here we look at the comorbidities (Figure A3) and the covariates such as lab values (Figure 4) for inpatient deterioration. Factors associated with ED to inpatient transition are mostly consistent with the factors associated with ICU transfer or in-hospital mortality. A recent study has found that COVID19 patients with dementia have a higher rate of hospitalization and mortality compared to COVID-19 patients without dementia. It includes potential reasons for this finding [28] but this study did not find dementia to be associated with patient deterioration after adjusting for age, in contrast to the ED admission case, where a positive association was found. Studying Figure $4 b$, the analysis of deterioration within $4 h$, shows the leading risks to be the need for oxygen support and respiratory rate. These are perhaps rather expected; however, still relatively high on the list is an altered mental status. This finding may point to the need for an additional risk analysis by the treating physician based upon pre-existing, and developing, mental faculty conditions that may not be typically brought to attention as much as pulmonary and cardiovascular review.

Comparing the covariates associated with patient deterioration at 4 and $12 \mathrm{~h}$, shown in Figure $4 a, b$, we see very similar patterns, though some subtle differences, for example the logistic regression log-odds ratio for the respiratory rate increasing from 0.45 to 0.72 between these time points. 
This work had some limitations. Unstructured data (e.g., progress notes, readings of CT scans) were not incorporated into the analysis. This type of data might clarify other factors related to the decision to admit. Also, regarding ED bounce-backs and inpatient transition to higher acuity, we did not try to quantify the patient's clinical stage of presentation with a systematic scoring algorithm, which may have revealed contributing factors to disease trajectory. Finally, for the multivariate analyses, it was found that the exact variables included in the fits were dependent on the "in" and "out" parameters for the stepwise regression procedure and therefore the results are dependent on the specifics of the analysis method.

\section{Conclusions}

Confirmation of the hypothesis was achieved; several clinical measurements and conditions were able to be identified as associated with care transitions among COVID-19 patients. During the investigation, this study produced a baseline analysis of clinical covariates and comorbidities with respect to organizing and statistically ranking, the findings related to both positive and negative risk. Some of the same risk factors were present for the transition from ED to inpatient as from inpatient to deterioration (ICU or death). In addition, sub-analyses looking at bounce-back admissions were also presented for both positive and negative risk. Furthermore, a multivariate analysis of the transitions and sub-analyses also revealed a few similarities and differences relative to univariate.

The logistic regression log-odd ratios data presented in this work deserve further contemplation and review. It could promote further investigation, as some findings may be either confirmatory or unexpected regarding relative strength or direction. We look forward to advancements in understanding of how the presence of particular comorbidities and covariates such as lab values, can help guide the care and resource utilization related to COVID-19 patients. Future work by this team may include further analysis of demographic factors which influence transitions of care, a generalized additive model of certain parameters, and/or an analysis of the presented results during other waves of the pandemic.

Author Contributions: Conceptualization, D.S., G.B., K.T., D.P.N. and C.A.; Data curation, G.B., K.T., D.P.N., S.R., E.G. and C.A.; Funding acquisition, M.X., P.T. and L.W.; Investigation, G.B., K.T., D.P.N., S.R., E.G. and J.D.C.; Methodology, D.S., J.D.C. and C.A.; Resources, M.X. and L.W.; Software, G.B., K.T. and D.P.N.; Supervision, M.X. and L.W.; Validation, S.R.; Visualization, K.T. and D.P.N.; Writing-original draft, D.S., G.B., K.T., D.P.N., S.R. and C.A.; Writing - review \& editing, D.S., G.B., K.T., D.P.N., S.R., E.G., M.X., L.W., J.D.C., P.T. and C.A. All authors have read and agreed to the published version of the manuscript.

Funding: This research was funded by Philips Research and Banner Health.

Institutional Review Board Statement: The study was conducted according to the guidelines of the Declaration of Helsinki and approved by the Banner Health Institutional Review Board (Project \# 01-14-0080 Technology Development for Monitoring Recommendation and Deterioration Detection Across the Care Continuum, approved 26 June 2019 and re-approved 6 June 2020).

Informed Consent Statement: Patient consent was waived due to the use of retrospective, deidentified patient data.

Data Availability Statement: Restrictions apply to the availability of these data. Data was obtained from Banner Health and are only available with the appropriate legal and ethical permissions.

Acknowledgments: We thank Ali Samadani of Philips Research for a careful reading of the manuscript and for offering helpful suggestions for improvements.

Conflicts of Interest: Greg Boverman, K.T., David Noren, Shreyas Ravindranath, Erina Ghosh, Minnan $\mathrm{Xu}$, Lisa Wondrely are employees of Philips, a medical device company. 


\section{Appendix A}

Table A1. ED patient characteristics (age, race, ethnicity, sex), ED length of stay, and outcomes. The "Missing" categories were not included in the calculation of proportions or statistical analysis.

\begin{tabular}{|c|c|c|c|c|c|c|c|c|}
\hline Feature & & Overall & $\begin{array}{l}\text { Discharged to } \\
\text { Home and } \\
\text { Not Admitted } \\
\text { within } 72 \text { h (A) }\end{array}$ & $\begin{array}{l}\text { Discharged to } \\
\text { Home and } \\
\text { Admitted } \\
\text { within } 72 \mathrm{~h} \text { (B) }\end{array}$ & $\begin{array}{c}\text { Admitted } \\
\text { within Same } \\
\text { Encounter (C) }\end{array}$ & $\begin{array}{l}\text { Admitted } \\
\text { within } 72 \mathrm{~h} \\
\text { (B\&C) }\end{array}$ & $\begin{array}{c}\text { Comparison } \\
\mathbf{1} \\
\text { (A vs. } \\
\text { B\&C) } \\
p \text {-Value }\end{array}$ & $\begin{array}{c}\text { Comparison } \\
2 \\
\text { (A vs. B) } \\
p \text {-Value }\end{array}$ \\
\hline$n$ & & 10,079 & 4907 & 157 & 5015 & 5172 & & \\
\hline $\begin{array}{c}\text { Age (years), } \\
\text { mean (SD) }\end{array}$ & & $51.6(19.5)$ & 42.4 (16.9) & $53.7(17.2)$ & 60.5 (17.6) & 60.3 (17.6) & $<0.001$ & $<0.001$ \\
\hline Race, $n(\%)$ & $\begin{array}{c}\text { American } \\
\text { Indian or } \\
\text { Alaska } \\
\text { Native } \\
\text { Black or } \\
\text { African } \\
\text { American } \\
\text { Other } \\
\text { White } \\
\text { Missing }\end{array}$ & $\begin{array}{c}392(4.6) \\
\\
606(7.0) \\
922(10.7) \\
6692(77.7) \\
1467(-)\end{array}$ & $\begin{array}{c}185(4.5) \\
304(7.5) \\
460(11.3) \\
3128(76.7) \\
-\end{array}$ & 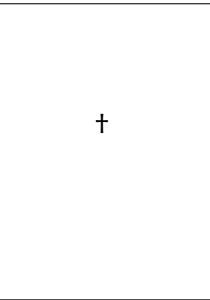 & $t$ & $\begin{array}{c}207(4.6) \\
302(6.7) \\
462(10.2) \\
3564(78.6) \\
-\end{array}$ & 0.15 & 0.961 \\
\hline $\begin{array}{l}\text { Ethnicity, } n \\
(\%)\end{array}$ & $\begin{array}{l}\text { Hispanic } \\
\text { or Latino } \\
\text { Not } \\
\text { Hispanic } \\
\text { or Latino } \\
\text { Missing }\end{array}$ & $\begin{array}{c}4623(49.0) \\
4816(51.0) \\
640(-)\end{array}$ & $\begin{array}{c}2526(55.2) \\
2051(44.8) \\
-\end{array}$ & t & $\dagger$ & $\begin{array}{c}2097(43.1) \\
2765(56.9) \\
-\end{array}$ & $<0.001$ & 0.114 \\
\hline Sex, $n(\%)$ & $\begin{array}{l}\text { Female } \\
\text { Male } \\
\text { Missing }\end{array}$ & $\begin{array}{c}5359(53.2) \\
4719(46.8) \\
1(-)\end{array}$ & $\begin{array}{c}2797(57.0) \\
2110(43.0) \\
-\end{array}$ & + & $t$ & $\begin{array}{c}2562(49.5) \\
2609(50.5) \\
-\end{array}$ & $<0.001$ & 0.206 \\
\hline $\begin{array}{l}\text { ED length of } \\
\text { stay (h), } \\
\text { mean (SD) }\end{array}$ & & $7.3(21.4)$ & $3.9(6.4)$ & $4.9(5.0)$ & $10.6(29.1)$ & $10.5(28.7)$ & $<0.001$ & 0.023 \\
\hline $\begin{array}{c}\text { Mortality, } n \\
(\%)\end{array}$ & & & -NA- & $11(7.0)$ & 446 (8.9) & $457(8.8)$ & & \\
\hline $\begin{array}{c}\text { ICU admit, } \\
(\%)\end{array}$ & & & -NA- & $27(17.2)$ & 1081 (21.6) & 1108 (21.4) & & \\
\hline $\begin{array}{l}\text { Hospital } \\
\text { Length of } \\
\text { Stay (h), } \\
\text { mean (SD) }\end{array}$ & & & -NA- & $179.4(152.0)$ & 157.5 (146.9) & $158.3(147.1)$ & & \\
\hline
\end{tabular}

SD: standard deviation. + : Withheld due to low counts (<100). -NA-: Not Applicable because patients were discharged to home.

Table A2. Demographic characteristics of non-critical inpatients with and without deterioration outcomes. The "Missing" categories were not included in the calculation of proportions or statistical analysis. SD: standard deviation.

\begin{tabular}{|c|c|c|c|c|c|}
\hline Feature & & Overall & $\begin{array}{l}\text { Admitted to ICU } \\
\text { or Died in } \\
\text { Hospital (E) }\end{array}$ & $\begin{array}{l}\text { Not Admitted to } \\
\text { ICU or Died in } \\
\text { Hospital (D) }\end{array}$ & $\begin{array}{l}\text { Comparison } 3 \text { (D } \\
\text { vs. E) } p \text {-Value }\end{array}$ \\
\hline$n$ & & 4766 & 970 & 3796 & \\
\hline $\begin{array}{l}\text { Age (years), mean } \\
\text { (SD) }\end{array}$ & & $59.8(18.5)$ & $66.5(18.3)$ & $58.1(18.2)$ & $<0.001$ \\
\hline \multirow{4}{*}{ Race, $n(\%)$} & \multirow{4}{*}{$\begin{array}{c}\text { American Indian or } \\
\text { Alaska Native } \\
\text { Black or African } \\
\text { American } \\
\text { Other } \\
\text { White } \\
\text { Missing }\end{array}$} & $261(6.3)$ & $42(5.0)$ & $219(6.6)$ & \multirow{4}{*}{0.117} \\
\hline & & $267(6.4)$ & $44(5.2)$ & $223(6.7)$ & \\
\hline & & $419(10.0)$ & $86(10.2)$ & $333(10.0)$ & \\
\hline & & $3228(77.3)$ & $673(79.6)$ & $2555(76.7)$ & \\
\hline \multirow{4}{*}{ Ethnicity, $n(\%)$} & \multirow{4}{*}{$\begin{array}{c}\text { Hispanic or Latino } \\
\text { Not Hispanic or } \\
\text { Latino } \\
\text { Missing }\end{array}$} & $1792(402)$ & $324(359)$ & $1468(413)$ & \multirow{4}{*}{0.004} \\
\hline & & $1 / 92(40.2)$ & $324(35.9)$ & $1468(41.3)$ & \\
\hline & & $2669(59.8)$ & $579(64.1)$ & 2090 (58.7) & \\
\hline & & $305(-)$ & & & \\
\hline \multirow{3}{*}{ Sex, $n(\%)$} & Female & $2456(51.5)$ & $420(43.3)$ & $2036(53.6)$ & \multirow{3}{*}{$<0.001$} \\
\hline & Male & $2310(48.5)$ & $550(56.7)$ & $1760(46.4)$ & \\
\hline & Missing & $0(-)$ & & & \\
\hline
\end{tabular}




\section{Appendix B}

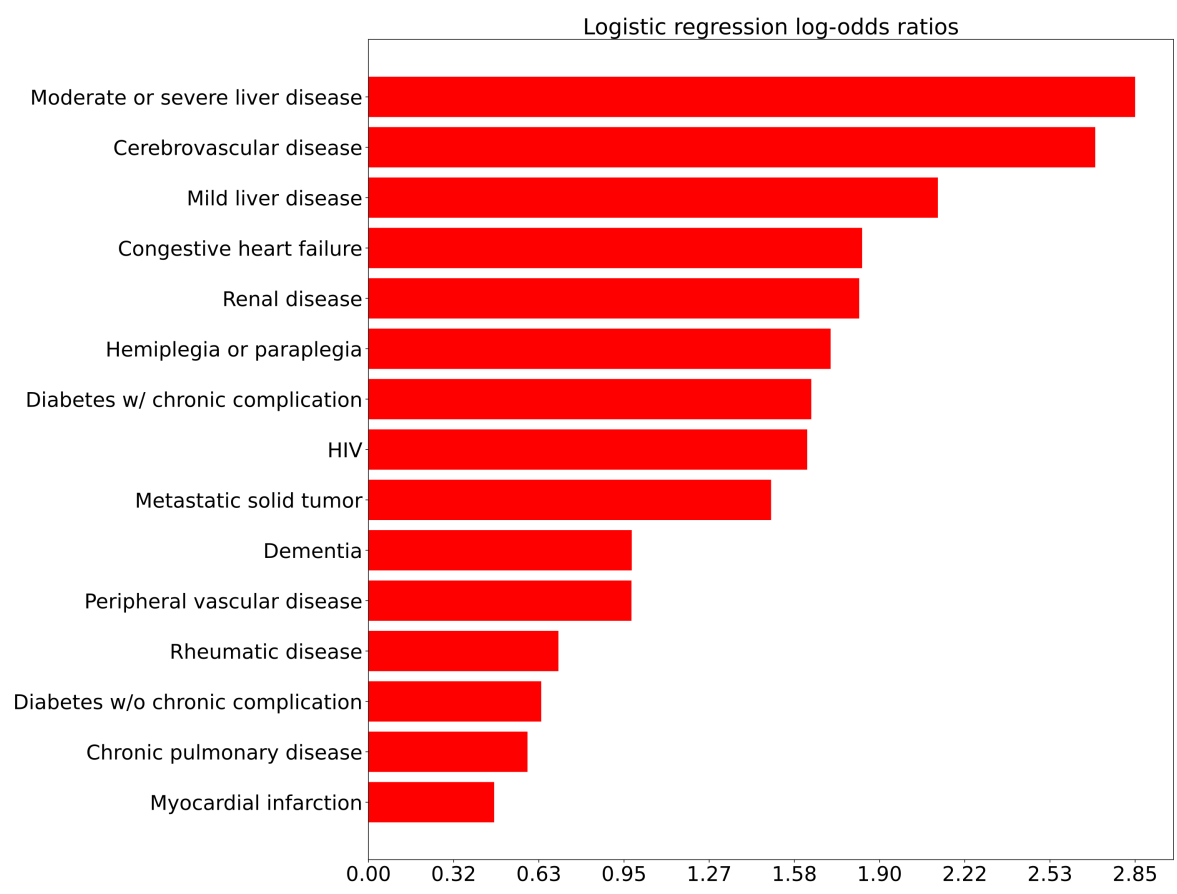

Figure A1. Logistic regression log odds ratios of comorbidities for Comparison 1 (ED admission) adjusted for age.

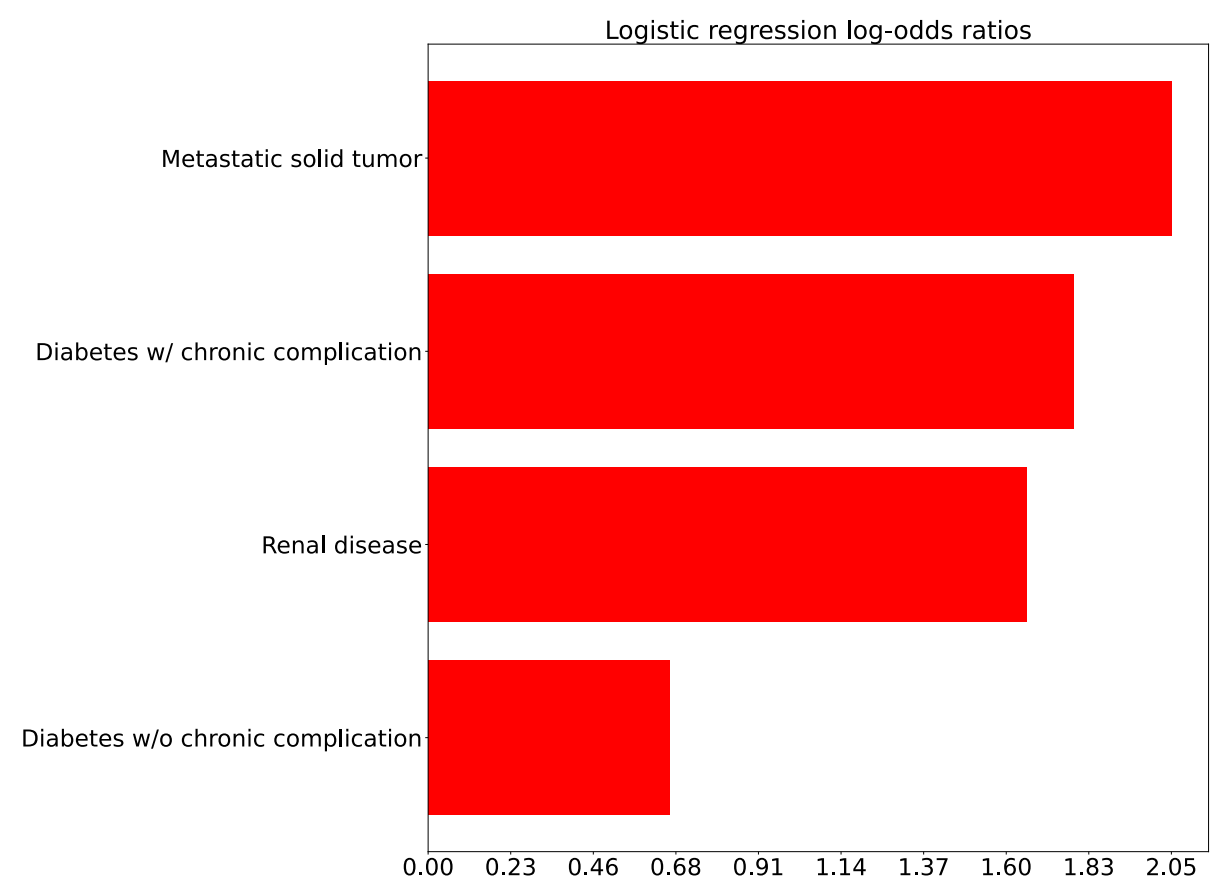

(a)

Figure A2. Cont. 
Logistic regression log-odds ratios

\section{Diabetes w/ chronic complication}

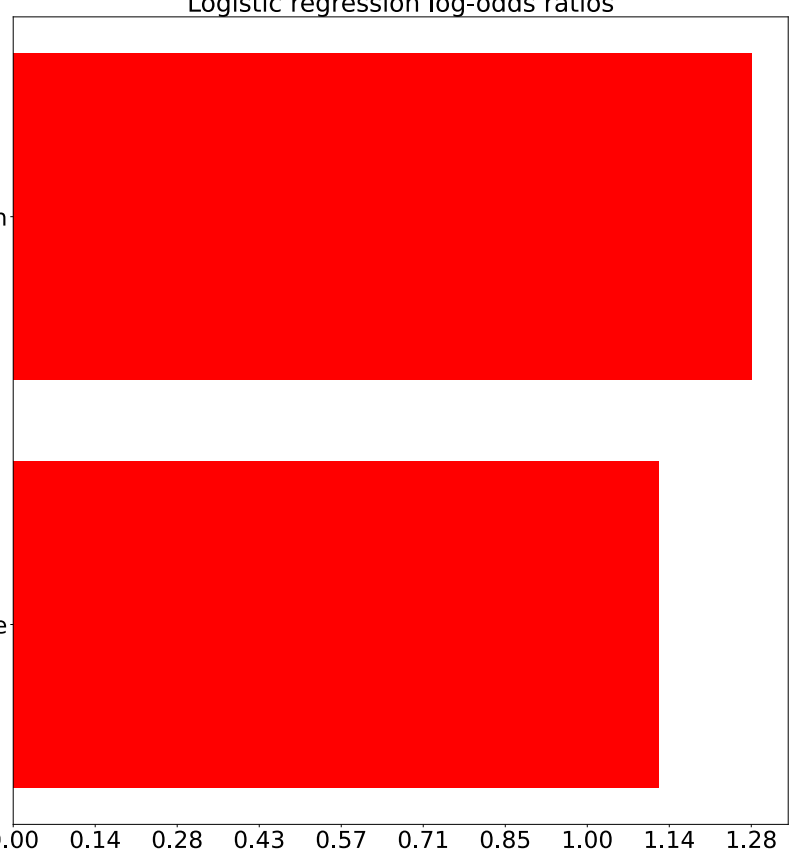

(b)

Figure A2. Logistic regression log-odds ratio correlating comorbidities to the outcome for comparison 2: (a) Raw log odds ratios and (b) Controlled for age.

\section{Appendix C}

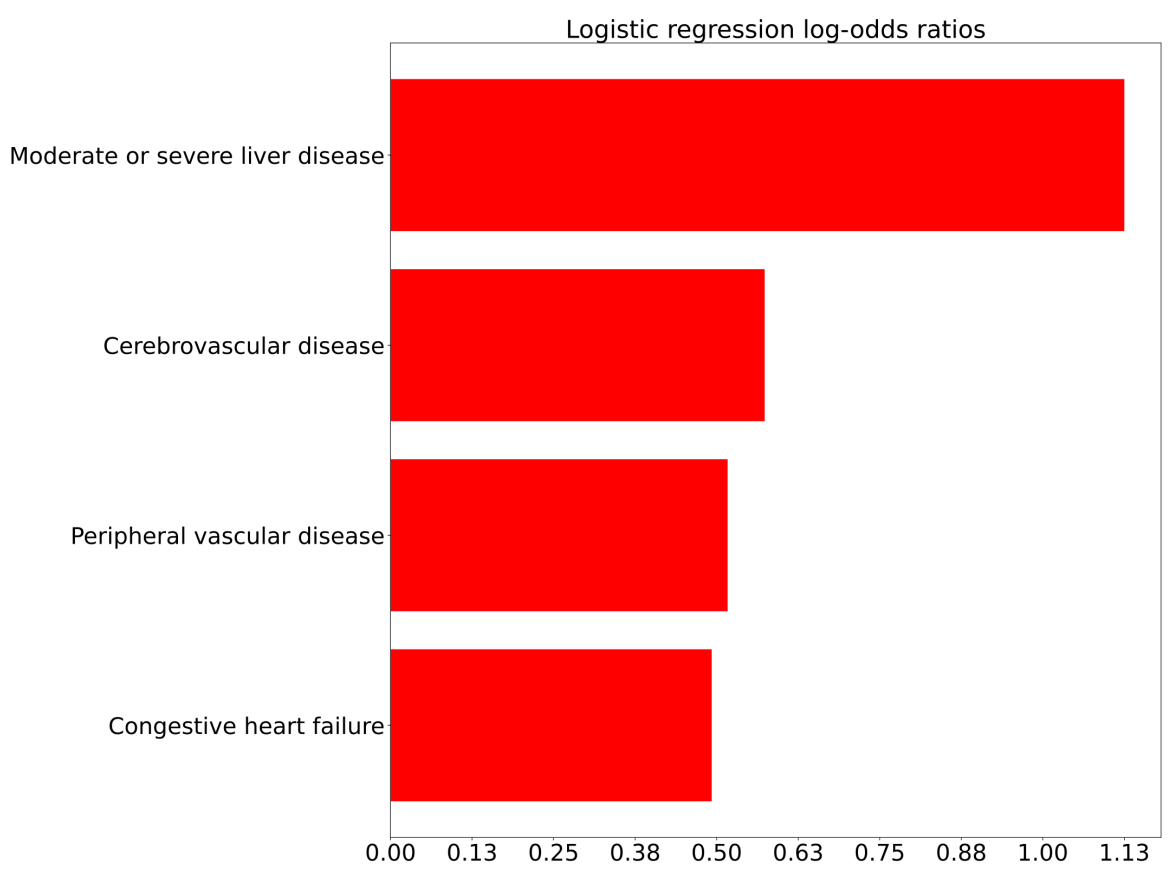

Figure A3. Logistic log-odds coefficients correlating comorbidities to the outcome for Comparison 3 (inpatient deterioration), controlling for age. 
Table A3. Multivariate coefficients and $p$-values for Comparison 1 (ED admission).

\begin{tabular}{lcc}
\hline \multicolumn{1}{c}{ Feature } & Coefficient & $p$-Value \\
\hline Oxygen support & 2.19 & $<0.001$ \\
\hline Age & 0.54 & $<0.001$ \\
\hline headache & -0.52 & $<0.001$ \\
\hline Fatigue & 0.58 & $<0.001$ \\
\hline Neutrophils count & 0.39 & $<0.001$ \\
\hline Anion gap & 0.38 & $<0.001$ \\
\hline SpO2 & -0.35 & $<0.001$ \\
\hline New or worsening cough & -0.33 & $<0.001$ \\
\hline eGFR & -0.31 & $<0.001$ \\
\hline Lymphocytes \% & 0.27 & $<0.001$ \\
\hline Respiratory Rate & 0.26 & $<0.001$ \\
\hline Temperature (core body) & 0.23 & $<0.001$ \\
\hline Calcium & -0.22 & $<0.001$ \\
\hline Platelets: Lymphocytes & 0.21 & $<0.001$ \\
\hline ALP & 0.21 & $<0.001$ \\
\hline Hgb & -0.19 & $<0.001$ \\
\hline Glucose & 0.17 & $<0.001$ \\
\hline Eosinophils \% & 0.14 & $<0.001$ \\
\hline Systolic BP & -0.13 & $<001$ \\
\hline & & \\
\hline & & \\
\hline
\end{tabular}

Table A4. Multivariate coefficients and $p$-values for Comparison 2 (ED bounce-back).

\begin{tabular}{ccc}
\hline Feature & Coefficient & $p$-Value \\
\hline Fatigue & 0.59 & 0.008 \\
\hline Platelet count & -0.39 & $<0.001$ \\
\hline Neutrophils \% & 0.33 & $<0.001$ \\
\hline Age & 0.33 & $<0.001$ \\
\hline Diastolic BP & -0.23 & 0.009 \\
\hline Anion gap & 0.19 & 0.006 \\
\hline SpO2 & -0.19 & 0.003
\end{tabular}




\section{Appendix D}

Table A5. Multivariate regression coefficients for comparison 3, $12 \mathrm{~h}$ prior to the event.

\begin{tabular}{lcc}
\hline \multicolumn{1}{c}{ Feature } & Coefficient & $p$-Value \\
\hline Oxygen support & 1.68 & $<0.001$ \\
\hline Heart Rate & 0.53 & $<0.001$ \\
\hline Respiratory Rate & 0.45 & $<0.001$ \\
\hline Neutrophils \% & 0.43 & $<0.001$ \\
\hline SpO2 & -0.38 & $<0.001$ \\
\hline Age & 0.36 & $<0.001$ \\
\hline Anion gap & 0.31 & $<0.001$ \\
\hline GCS & -0.31 & $<0.001$ \\
\hline Temperature (core body) & 0.26 & $<0.001$ \\
\hline Platelet count & -0.22 & $<0.001$ \\
\hline Calcium & -0.18 & 0.001 \\
\hline BUN:Creatinine & 0.16 & 0.004 \\
\hline Diastolic BP & -0.16 & 0.004 \\
\hline RDW SD & 0.13 & 0.01 \\
\hline WBC & 0.12 & $<0.01$ \\
\hline Bilirubin total & 0.12 & 0.004 \\
\hline
\end{tabular}

Table A6. Multivariate regression coefficients for comparison 3, $4 \mathrm{~h}$ prior to the event.

\begin{tabular}{lcc}
\hline \multicolumn{1}{c}{ Feature } & Coefficient & $p$-Value \\
\hline Oxygen support & 1.31 & $<0.001$ \\
\hline Respiratory Rate & 0.72 & $<0.001$ \\
\hline SpO2 & -0.58 & $<0.001$ \\
\hline Heart Rate & 0.50 & $<0.001$ \\
\hline Anion gap & 0.45 & $<0.001$ \\
\hline Lymphocytes \% & -0.38 & $<0.001$ \\
\hline GCS & -0.34 & $<0.001$ \\
\hline Age & 0.34 & $<0.001$ \\
\hline Temperature (core body) & 0.26 & $<0.001$ \\
\hline Platelet count & -0.26 & $<0.001$ \\
\hline RDW CV & 0.17 & $<0.001$ \\
\hline Systolic BP & -0.16 & 0.002 \\
\hline Neutrophils:Lymphocytes & 0.15 & 0.006 \\
\hline Lymphocytes count & 0.12 & 0.006 \\
\hline
\end{tabular}


Table A7. Ranks and numbers of times covariates appear in the various multivariate models.

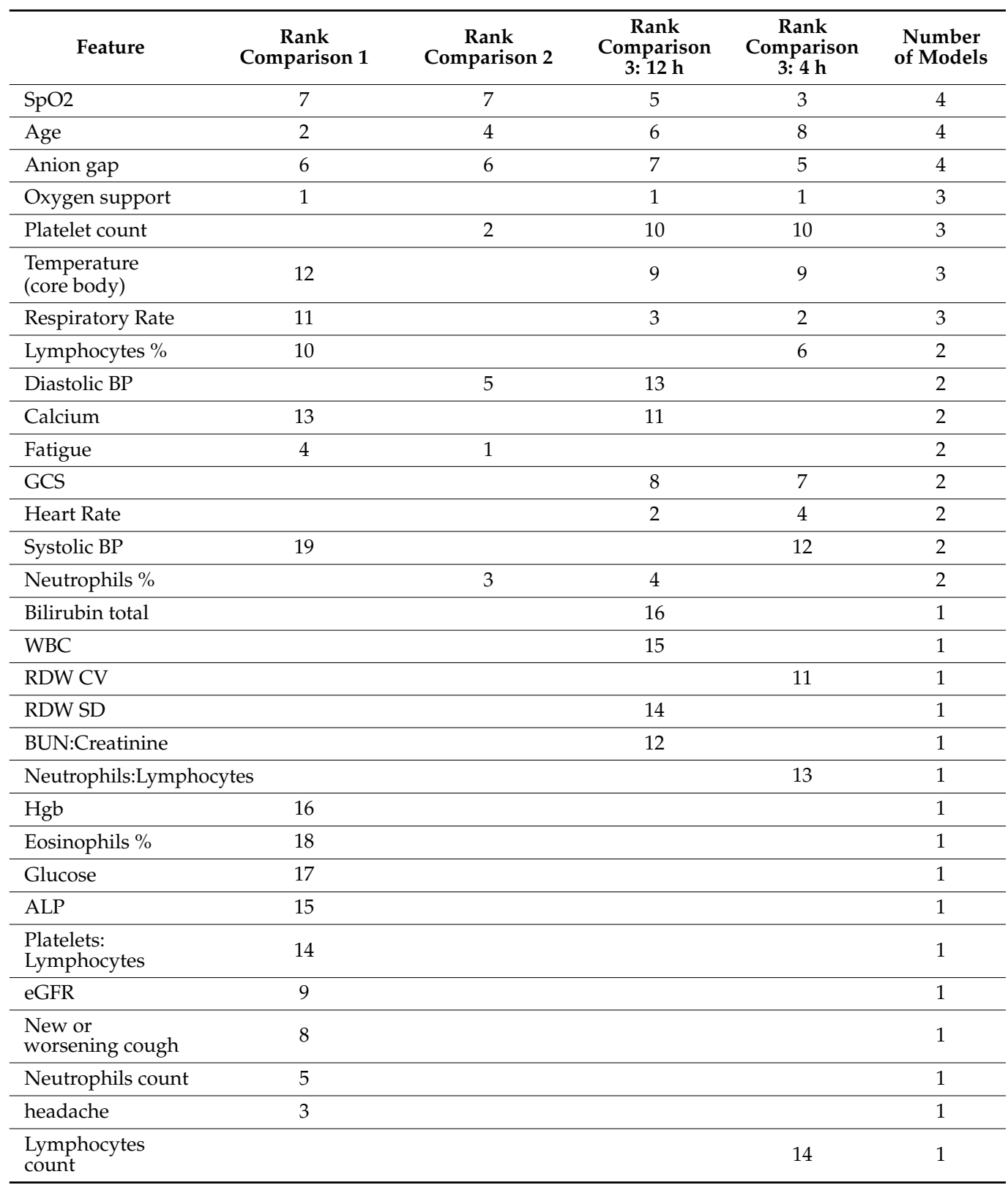

\section{References}

1. WHO Coronavirus Disease (COVID-19) Dashboard. Available online: https:/ / covid19. who.int (accessed on 22 June 2021).

2. Chavez, S.; Long, B.; Koyfman, A.; Liang, S.Y. Coronavirus Disease (COVID-19): A Primer for Emergency Physicians. Am. J. Emerg. Med. 2020, 44, 220-229. [CrossRef]

3. Whiteside, T.; Kane, E.; Aljohani, B.; Alsamman, M.; Pourmand, A. Redesigning Emergency Department Operations amidst a Viral Pandemic. Am. J. Emerg. Med. 2020, 38, 1448-1453. [CrossRef]

4. Kleinpell, R.; Ferraro, D.M.; Maves, R.C.; Gill, S.L.K.; Branson, R.; Greenberg, S.; Doersam, J.K.; Raman, R.; Kaplan, L.J. Coronavirus Disease 2019 Pandemic Measures: Reports From a National Survey of 9,120 ICU Clinicians. Crit Care Med. 2020, 48, e846-e855. [CrossRef]

5. $\quad$ Sprung, C.L.; Zimmerman, J.L.; Christian, M.D.; Joynt, G.M.; Hick, J.L.; Taylor, B.; Richards, G.A.; Sandrock, C.; Cohen, R.; Adini, B. Recommendations for Intensive Care Unit and Hospital Preparations for an Influenza Epidemic or Mass Disaster: Summary Report of the European Society of Intensive Care Medicine's Task Force for Intensive Care Unit Triage during an Influenza Epidemic or Mass Disaster. Intensive Care Med. 2010, 36, 428-443. [CrossRef]

6. $\quad$ Sprung, C.L.; Joynt, G.M.; Christian, M.D.; Truog, R.D.; Rello, J.; Nates, J.L. Adult ICU Triage During the Coronavirus Disease 2019 Pandemic: Who Will Live and Who Will Die? Recommendations to Improve Survival*. Crit Care Med. 2020, 48, 1196-1202. [CrossRef] [PubMed] 
7. Zhou, F.; Yu, T.; Du, R.; Fan, G.; Liu, Y.; Liu, Z.; Xiang, J.; Wang, Y.; Song, B.; Gu, X.; et al. Clinical Course and Risk Factors for Mortality of Adult Inpatients with COVID-19 in Wuhan, China: A Retrospective Cohort Study. The Lancet 2020, 395, 1054-1062. [CrossRef]

8. Grasselli, G.; Zangrillo, A.; Zanella, A.; Antonelli, M.; Cabrini, L.; Castelli, A.; Cereda, D.; Coluccello, A.; Foti, G.; Fumagalli, R.; et al. Baseline Characteristics and Outcomes of 1591 Patients Infected With SARS-CoV-2 Admitted to ICUs of the Lombardy Region, Italy. JAMA 2020, 323, 1574-1581. [CrossRef]

9. Richardson, S.; Hirsch, J.S.; Narasimhan, M.; Crawford, J.M.; McGinn, T.; Davidson, K.W.; Consortium and the NC.-19 R.; Barnaby, D.P.; Becker, L.B.; Chelico, J.D.; et al. Presenting Characteristics, Comorbidities, and Outcomes Among 5700 Patients Hospitalized With COVID-19 in the New York City Area. JAMA 2020, 323, 2052-2059. [CrossRef]

10. Pollard, T.J.; Johnson, A.E.W.; Raffa, J.D.; Mark, R.G. Tableone: An Open Source Python Package for Producing Summary Statistics for Research Papers. JAMIA Open 2018, 1, 26-31. [CrossRef] [PubMed]

11. Van Rossum, G.; Drake, F.L. Python 3 Reference Manual; CreateSpace: Scotts Valley, CA, USA, 2009.

12. Quan, H.; Li, B.; Couris, C.M.; Fushimi, K.; Graham, P.; Hider, P.; Januel, J.-M.; Sundararajan, V. Updating and Validating the Charlson Comorbidity Index and Score for Risk Adjustment in Hospital Discharge Abstracts Using Data from 6 Countries. Am. J. Epidemio. 2011, 173, 676-682. [CrossRef] [PubMed]

13. R Core Team. R: A Language and Environment for Statistical Computing; R Foundation for Statistical Computing: Vienna, Austria, 2020.

14. Calmes, D.; Graff, S.; Maes, N.; Frix, A.-N.; Thys, M.; Bonhomme, O.; Berg, J.; Debruche, M.; Gester, F.; Henket, M.; et al. Asthma and COPD Are Not Risk Factors for ICU Stay and Death in Case of SARS-CoV2 Infection. J. Allergy Clin. Immunol. Pract. 2021, 9 , 160-169. [CrossRef] [PubMed]

15. Sabatino, J.; Rosa, S.D.; Salvo, G.D.; Indolfi, C. Impact of Cardiovascular Risk Profile on COVID-19 Outcome. A Meta-Analysis. PLoS ONE 2020, 15, e0237131. [CrossRef]

16. Velavan, T.P.; Meyer, C.G. Mild versus Severe COVID-19: Laboratory Markers. Int J. Infect. Dis 2020, 95, 304-307. [CrossRef]

17. Zhang, L.; Yan, X.; Fan, Q.; Liu, H.; Liu, X.; Liu, Z.; Zhang, Z. D-Dimer Levels on Admission to Predict in-Hospital Mortality in Patients with Covid-19. J. Thromb Haemost 2020, 18, 1324-1329. [CrossRef]

18. Yao, Y.; Cao, J.; Wang, Q.; Shi, Q.; Liu, K.; Luo, Z.; Chen, X.; Chen, S.; Yu, K.; Huang, Z.; et al. D-Dimer as a Biomarker for Disease Severity and Mortality in COVID-19 Patients: A Case Control Study. J. Intensive Care 2020, 8, 49. [CrossRef]

19. Yu, H.-H.; Qin, C.; Chen, M.; Wang, W.; Tian, D.-S. D-Dimer Level Is Associated with the Severity of COVID-19. Thromb Res. 2020, 195, 219-225. [CrossRef]

20. Foy, B.H.; Carlson, J.C.T.; Reinertsen, E.; Padros, I.; Valls, R.; Pallares Lopez, R.; Palanques-Tost, E.; Mow, C.; Westover, M.B.; Aguirre, A.D.; et al. Association of Red Blood Cell Distribution Width With Mortality Risk in Hospitalized Adults With SARS-CoV-2 Infection. JAMA Netw. Open 2020, 3, e2022058. [CrossRef]

21. Lorente, L.; Martín, M.M.; Argueso, M.; Solé-Violán, J.; Perez, A.; Marcos, Y.; Ramos, J.A.; Ramos-Gómez, L.; López, S.; Franco, A.; et al. Association between Red Blood Cell Distribution Width and Mortality of COVID-19 Patients. Anaesth. Crit. Care Pain Med. 2020, 40, 100777. [CrossRef]

22. Karampitsakos, T.; Akinosoglou, K.; Papaioannou, O.; Panou, V.; Koromilias, A.; Bakakos, P.; Loukides, S.; Bouros, D.; Gogos, C.; Tzouvelekis, A. Increased Red Cell Distribution Width Is Associated With Disease Severity in Hospitalized Adults With SARS-CoV-2 Infection: An Observational Multicentric Study. Front. Med. 2020, 7. [CrossRef] [PubMed]

23. Bloom, P.P.; Meyerowitz, E.A.; Reinus, Z.; Daidone, M.; Gustafson, J.; Kim, A.Y.; Schaefer, E.; Chung, R.T. Liver Biochemistries in Hospitalized Patients With COVID-19. Hepatology 2021, 73, 890-900. [CrossRef] [PubMed]

24. Razavian, N.; Major, V.J.; Sudarshan, M.; Burk-Rafel, J.; Stella, P.; Randhawa, H.; Bilaloglu, S.; Chen, J.; Nguy, V.; Wang, W.; et al. A Validated, Real-Time Prediction Model for Favorable Outcomes in Hospitalized COVID-19 Patients. NPJ Digit. Med. 2020, 3 , 1-13. [CrossRef] [PubMed]

25. Carlino, M.V.; Valenti, N.; Cesaro, F.; Costanzo, A.; Cristiano, G.; Guarino, M.; Sforza, A. Predictors of Intensive Care Unit Admission in Patients with Coronavirus Disease 2019 (COVID-19). Monaldi Arch. Chest Dis. 2020, 90. [CrossRef] [PubMed]

26. Tavakolpour, S.; Rakhshandehroo, T.; Wei, E.X.; Rashidian, M. Lymphopenia during the COVID-19 Infection: What It Shows and What Can Be Learned. Immunol. Lett. 2020, 225, 31-32. [CrossRef] [PubMed]

27. Zhu, S.; Dong, L.; Cai, W. Predictive Value of Neutrophil to Lymphocyte and Platelet to Lymphocyte Ratio in COVID-19. Critical Care 2020, 24, 532. [CrossRef] [PubMed]

28. Wang, Q.; Davis, P.B.; Gurney, M.E.; Xu, R. COVID-19 and Dementia: Analyses of Risk, Disparity, and Outcomes from Electronic Health Records in the US. Alzheimer's Dement. 2021, 17, 1297-1306. [CrossRef] 